\title{
Impact of total cumulative glucocorticoid dose on bone mineral density in patients with 21-hydroxylase deficiency
}

\author{
Zeina Chakhtoura ${ }^{1}$, Anne Bachelot ${ }^{1}$, Dinane Samara-Boustani ${ }^{2}$, Jean-Charles Ruiz ${ }^{1}$, Bruno Donadille ${ }^{3}$, \\ Jérôme Dulon ${ }^{1}$, Sophie Christin-Maître ${ }^{3}$, Claire Bouvattier ${ }^{4}$, Marie-Charles Raux-Demay ${ }^{5}$, Philippe Bouchard ${ }^{3}$, \\ Jean-Claude Carel ${ }^{6}$, Juliane Leger ${ }^{6}$, Frédérique Kuttenn ${ }^{1,7}$, Michel Polak ${ }^{2,7}$ and Philippe Touraine ${ }^{1,7}$ \\ ${ }^{1}$ AP-HP, Department of Endocrinology and Reproductive Medicine, Groupe Hospitalier Pitié-Salpêtrière, 47-83 boulevard de l'Hôpital, 75651 Paris Cedex \\ 13, France, ${ }^{2}$ Department of Pediatric Endocrinology, Hôpital Necker-Enfants Malades, Paris, France, ${ }^{3}$ Department of Endocrinology, Hôpital Saint- \\ Antoine, Paris, France, ${ }^{4}$ Department of Pediatric Endocrinology, Hôpital Saint-Vincent de Paul, Paris, France, ${ }^{5}$ Department of Pediatric Endocrinology, \\ Hôpital Trousseau Malades, Paris, France, ${ }^{6}$ Departments of Pediatric Endocrinology, Hôpital Robert Debré, Paris, France and ${ }^{7}$ Inserm U845, University \\ Paris-Descartes, Faculty of Medicine René Descartes, 75015 Paris, France; on behalf of Centre des Maladies Endocriniennes Rares de la Croissance and \\ Association Surrénales
}

(Correspondence should be addressed to P Touraine; Email: philippe.touraine@psl.aphp.fr)

\begin{abstract}
Objective: It remains controversial whether long-term glucocorticoids are charged of bone demineralization in patients with congenital adrenal hyperplasia (CAH) due to 21-hydroxylase deficiency. The aim of this study was to know whether cumulative glucocorticoid dose from the diagnosis in childhood to adulthood in patients with CAH had a negative impact on bone mineral density (BMD).

Design: This was a retrospective study.

Methods: Thirty-eight adult patients with classical and non-classical CAH were included. BMD was measured in the lumbar spine and femoral neck. Total cumulative glucocorticoid (TCG) and total average glucocorticoid (TAG) doses were calculated from pediatric and adult files.

Results: We showed a difference between final and target heights $(-0.82 \pm 0.92$ s.D. for women and $-1.31 \pm 0.84$ S.D. for men; $P<0.001)$. Seventeen patients $(44.7 \%)$ had bone demineralization $(35.7 \%$ of women and $70 \%$ of men). The 28 women had higher BMD than the 10 men for lumbar $(-0.26 \pm 1.20 \mathrm{vs}$ $-1.25 \pm 1.33$ s.D.; $P=0.02)$ and femoral T-scores $(0.21 \pm 1.30$ s.D. versus $-1.08 \pm 1.10$ s.D.; $P=0.007)$. In the salt-wasting group, women were almost significantly endowed with a better BMD than men $(P=0.053)$. We found negative effects of TCG, TAG on lumbar $(P<0.001, P=0.002)$ and femoral T-scores $(P=0.006, P<0.001)$, predominantly during puberty. BMI was protective on BMD $(P=0.006)$.

Conclusion: The TCG is an important factor especially during puberty for a bone demineralization in patients with 21-hydroxylase deficiency. The glucocorticoid treatment should be adapted particularly at this life period and preventive measures should be discussed in order to limit this effect.
\end{abstract}

European Journal of Endocrinology 158 879-887

\section{Introduction}

The 21-hydroxylase deficiency is an autosomal recessive disease that constitutes $95 \%$ of the congenital adrenal hyperplasia $(\mathrm{CAH})$, the remaining $5 \%$ being due to other enzyme deficiencies. It is essentially responsible for impaired cortisol synthesis, which in turn leads to a positive feedback on CRH and adrenocorticotrophin $(\mathrm{ACTH})$, and increased production of androgens and steroid precursors upstream from the enzymatic defect (1).

There is a fine balance between androgen levels and glucocorticoid treatment, the goal of which is to lower androgen levels without making them plummet and bringing on associated side effects. What is more, chronic glucocorticoid therapy is known to generate bone loss in many ways: a direct suppression of osteoblastic activity (2) and an inhibition of digestive calcium absorption with secondary hyperparathyroidism and increased bone resorption by osteoclasts (3). Glucocorticoids also seem to regulate renal calcium excretion and parathormone secretion (4). Based on these findings, many studies have attempted to study bone mineralization status in patients with 21-hydroxylase deficiency, with the precise goal of identifying bone demineralization. Some studies reported no significant differences in bone mineral density (BMD) between patients and controls (5-9), whereas others found impaired BMD (10-15). These contradictory results may be explained by heterogeneous populations and methods. Indeed, a couple of studies included pre- and post-pubertal patients who had not yet reached their final height, while others sought to compare BMD with average glucocorticoid dose, at the time of the study.

To resolve this issue, we hypothesized that there could be a negative role of the total cumulative glucocorticoid (TCG) dose on BMD. To do so, we collected the daily treatment from the diagnosis in early infancy to inclusion in the 
study. We considered adult patients more than 16 years old with classical and non-classical $\mathrm{CAH}$ that had been revealed by precocious puberty and those who had been continuously monitored and treated since childhood.

\section{Patients and methods}

\section{Patients}

Sixty-one adult patients suffering from $\mathrm{CAH}$ due to 21-hydroxylase deficiency and treated since early infancy in pediatric centers were seen between 2003 and 2007 by the Department of Endocrinology and Reproduction Medicine $(n=53,87 \%)$, La Pitié-Salpêtrière Hospital and the Department of Endocrinology $(n=8,13 \%)$, St-Antoine Hospital, Paris, France. All patients had achieved full puberty and final height. The inclusion criteria were based on the availability of 1) dual-energy X-ray absorptiometry (DXA) and 2) complete patient files, thus enabling the calculation of the TCG treatment. Whereas 23 patients were not included because they simply underwent a BMD evaluation, 38 patients $(62.3 \%)$ met all criteria. Out of the 38 patients, $24(63.2 \%)$ have the salt-wasting form (SW; 14 women and 10 men), 5 the simple virilizing form (SV; $13.1 \%$, women only in this group), and 9 the non-classical form revealed by precocious puberty $(23.7 \%$, women only in this group). Mutation analysis of the cytochrome P450 21-hydroxylase (CYP21A2) gene confirmed the diagnosis in each case. All patients underwent a medical examination to determine height, weight, and body mass index (BMI). They had all been on glucocorticoid treatment since diagnosis in infancy and 23 of them (60.5\%) were also receiving mineralocorticoid ( $9 \alpha$-fludrocortisone) during the study. Out of the 28 women, 16 (57.1\%) had received exogenous estrogens at some point in their life. At the time of the study, six women were under $17 \beta$-estradiol and cyproterone acetate and nine under estroprogestative pills. None of the subjects presented other conditions known to affect bone metabolism. No fracture was recorded. Nobody was taking bisphonate, calcium, or vitamin D supplementation.

\section{Consulting files}

Retrospective research was done by consulting the pediatric files of Necker-Enfants Malades, St-Vincent de Paul and Trousseau Hospitals, Paris, France. We were able to research the pubertal profiles of 32 subjects. The onset of puberty was noted (B2 in girls (16) and testes size greater than $20 \times 30 \mathrm{~mm}$ in boys (17)) as well as height and bone age at the beginning of puberty. The age of menarche and the use of exogenous estrogens were recorded for women. The total pubertal growth was defined as growth from the onset of puberty until final height. Target height was calculated as (maternal height + paternal height $\pm 13 \mathrm{~cm}) / 2$ (18). All daily glucocorticoid treatment and yearly heights and weights were noted for each patient from day one of the diagnosis to BMD testing, based on both pediatric and adult files. We decided not to record selective hormonal data from childhood because the frequency and the type of hormonal samplings were very variable for all patients.

\section{Glucocorticoid treatment}

Doses of the various glucocorticoids were converted to growth-retarding cortisol equivalents (1 mg dexamethasone $=16 \mathrm{mg}$ prednisone $=80 \mathrm{mg}$ hydrocortisone; 10 , 12, 19). Each year, we summed every daily dose of treatment and divided the total by the corresponding body area and obtained annual cumulative doses of hydrocortisone $\left(\mathrm{mg} / \mathrm{m}^{2}\right.$ per $\left.\mathrm{yr}\right)$.

Each patient's TCG treatment (TCG in $\mathrm{mg} / \mathrm{m}^{2}$ ) was found by compiling these annual cumulative hydrocortisone doses.

Average daily hydrocortisone treatments $\left(\mathrm{mg} / \mathrm{m}^{2}\right.$ per $\left.\mathrm{d}\right)$ were determined every year.

We also calculated the mean daily dose of hydrocortisone that the patient received over his/her entire therapy life period: total average glucocorticoid (TAG in $\mathrm{mg} / \mathrm{m}^{2}$ per $\mathrm{d}$ ).

\section{BMD assessment}

The femoral neck and lumbar spine BMD were assessed by the same operator using a Hologic Densitometer Quantitative Digital Radiography (QDR) 1000. The daily quality control showed a $0.52 \%$ coefficient of variation during the realization of these tests. BMD results at the femoral neck and lumbar spine L2-L4 were evaluated and expressed as absolute values in $\mathrm{g} / \mathrm{cm}^{2}$ and T-scores ((BMD-Peak Bone Mass)/s.D). OFELY Caucasian reference curves were used to calculate women T-scores (20) and Hologic's TK91 norms were applied for men. Adjusting BMD regarding subjects' heights was not necessary, because they were in the normal range even if some did not reach their target heights. We were able to use T-scores to interpret and compare the results since all patients were less than 40 years old, and the general population's peak bone mass does not decrease at this age. We used WHO criteria to identify different degrees of low bone mass. We acknowledged that the descriptors were set up for postmenopausal women and defined as osteoporosis (T-score $<-2.5$ s.D.), osteopenia (T-score between -2.5 and -1 s.D.), and normal bone densitometry (T-score $>-1$ s.D.) (21).

\section{Statistical analysis}

Descriptive statistics were performed for each variable; quantitative results were presented as mean \pm s.D. and qualitative results as frequency. We accepted that all variables (except BMI) followed a normal distribution. The four groups (SW, SV, NC females, and SW males) were compared using ANOVA test (Kruskall-Wallis for BMI). 
When $P$ value was $<0.05$, Tukey's multiple comparison test was performed. A comparison between males and females was computed using Student's t-test and MannWhitney test for BMI. To assess the effect of treatment on BMD, with adjustment on covariates (gender, group, age, and BMI), a multivariate linear model was performed. Covariates were entered in the model using stepwise selection. Since BMD was characterized by two variables (lumbar and femoral T-scores), significance level was Bonferroni corrected: a $P<0.025$ was accepted as significant. Statistical analyses were performed using SAS 8.2 (SAS Institute, Cary, NC, USA) for Windows. Type I error was 0.05 for all analyses.

\section{Results}

\section{Population general characteristics}

Auxological data are shown in Table 1. All sub-groups of patients were comparable for age, the mean age being $24.6 \pm 5.9$ years (range: 16-39 years). We noted a lower treatment duration for non-classical $\mathrm{CAH}$ people (19.3 \pm 9.3 years, $P=0.09)$, but this population was probably not numerous enough to see a statistical difference with people suffering from classical $\mathrm{CAH}$, $22.7 \pm 6.9$ years being the entire population mean. Mean height was $1.59 \pm 0.06 \mathrm{~m}$ for women and $1.67 \pm$ $0.04 \mathrm{~m}$ for men. Median BMI was $24.7 \mathrm{~kg} / \mathrm{m}^{2}(19.4$ 38.6 ) for women and $23.3 \mathrm{~kg} / \mathrm{m}^{2}$ (19.1-37.3) for men, without any significant difference. The mean growthretarding current dose of hydrocortisone was $16.9 \pm$ $5.5 \mathrm{mg} / \mathrm{m}^{2}$ per d. Annual hydrocortisone equivalent doses from birth to 18 years old, corresponding to the pediatric period, are represented in Fig. 1. Age at diagnostic was 19.9 \pm 33.2 days for SW women, $45.9 \pm$ 58.1 days for SW men, 3.9 \pm 5.6 years for SV women, and $6.4 \pm 1.5$ years for NC women. Mean daily dose over a year could be distinguished in three periods: salt wasters were treated with $23.8 \pm 8.8 \mathrm{mg} / \mathrm{m}^{2}$ per $\mathrm{d}$ the first 2 years of life, patients with classical (SW and SV) and non-classical forms had respectively $18.2 \pm 4.8$ and $12.7 \pm 4.1 \mathrm{mg} / \mathrm{m}^{2}$ per d during childhood $(P<0.001)$ and $20.4 \pm 6.4$ and $13.8 \pm 3.0 \mathrm{mg} / \mathrm{m}^{2}$ per $\mathrm{d}$ during puberty $(P=0.01)$.

The 23 non-included patients for whom a TCG could not be calculated were significantly older $(31.8 \pm 8.2$ years, $P=0.002$ ) and therefore had longer treatment duration $(28.9 \pm 9.8$ years, $P=0.005)$ than the included ones. They were comparable for height, BMI, mean current dose of hydrocortisone (17.3 \pm $5.5 \mathrm{mg} / \mathrm{m}^{2}$ per $\mathrm{d}$ ), and BMD.

\section{Puberty data}

The onset of puberty was at $10.3 \pm 1.8$ years for girls and $11.6 \pm 1.6$ years for boys. The mean age of menarche was $13.6 \pm 1.6$ years, $3.1 \pm 2.1$ years after B2. The height at the start of puberty was $0.90 \pm 1.82$ S.D. Bone ages were available for half of the patients only and were not statistically different from chronological ages $(+0.6$ year for girls, $P=0.29$ and +0.9 year for boys, $P=0.26)$. Total pubertal growth for girls and boys was $18.5 \pm 8.5 \mathrm{~cm}$ and $18.5 \pm 5.5 \mathrm{~cm}$ respectively which is significantly less than in the reference population of Prader et al. (22) with a mean pubertal growth of $20.3 \pm 6.8 \mathrm{~cm}$ in females and $28.2 \pm 8.2 \mathrm{~cm}$ in males. We noted a significant difference between the final and target heights $(-0.82 \pm 0.92$ s.D for women and $-1.31 \pm 0.84$ s.D for men; $P<0.001)$.

\section{Bone mineral density}

The 28 women had significantly better values than the 10 men for lumbar T-score $(-0.26 \pm 1.20$ vs $-1.25 \pm$ 1.33 s.D.; $P=0.04)$ and femoral T-score $(0.21 \pm 1.30 \mathrm{vs}$ $-1.08 \pm 1.10$ S.D.; $P=0.009)$. This difference almost

Table 1 Clinical characteristics of the 38 included patients.

\begin{tabular}{|c|c|c|c|c|c|c|c|}
\hline & Number & Age (years) & $\begin{array}{l}\text { Treatment } \\
\text { duration } \\
\text { (years) }\end{array}$ & $\begin{array}{l}\text { Current dose of } \\
\text { hydrocortisone } \\
\left(\mathrm{mg} / \mathrm{m}^{2} \text { per d }\right)^{\mathrm{a}}\end{array}$ & Height (m/s.D.) & Weight $(\mathrm{kg})$ & BMI $\left(\mathrm{kg} / \mathrm{m}^{2}\right)^{\mathrm{b}}$ \\
\hline All patients & 38 & $24.6 \pm 5.9$ & $22.7 \pm 6.9$ & $16.9 \pm 5.5$ & $\begin{array}{l}1.61 \pm 0.06 / \\
\quad-0.94 \pm 0.95\end{array}$ & $66.5 \pm 14.0$ & $24.2(19.1-38.6)$ \\
\hline All females & 28 & $24.7 \pm 6.3$ & $22.1 \pm 7.6$ & $15.5 \pm 5.4$ & $\begin{array}{l}1.59 \pm 0.06 / \\
-0.80 \pm 0.99\end{array}$ & $65.7 \pm 14.0$ & $24.7(19.4-38.6)$ \\
\hline SW females & 14 & $23.5 \pm 5.5$ & $23.5 \pm 5.5$ & $15.2 \pm 4.2$ & $\begin{array}{l}1.59 \pm 0.05 / \\
\quad-0.84 \pm 0.82\end{array}$ & $64.7 \pm 12.3$ & $24.7(19.4-32.9)$ \\
\hline SV females & 5 & $27.0 \pm 5.7$ & $23.4 \pm 9.7$ & $20.1 \pm 2.9$ & $\begin{array}{l}1.56 \pm 0.07 / \\
\quad-1.38 \pm 1.29\end{array}$ & $63.3 \pm 15.5$ & $22.0(21.2-37.9)$ \\
\hline NC females & 9 & $25.3 \pm 8.0$ & $19.3 \pm 9.3$ & $13.4 \pm 6.7$ & $\begin{array}{l}1.61 \pm 0.06 / \\
\quad-0.41 \pm 1.01\end{array}$ & $68.5 \pm 16.9$ & $25.4(19.9-38.6)$ \\
\hline All males & 10 & $24.2 \pm 4.5$ & $24.2 \pm 4.5$ & $20.4 \pm 4.3$ & $\begin{array}{l}1.67 \pm 0.04^{*} / \\
-1.35 \pm 0.70\end{array}$ & $69.0 \pm 14.4^{*}$ & $23.3(19.1-37.3)$ \\
\hline
\end{tabular}

SW, salt wasting; SV, simple virilizing; NC, non-classical. *Significant difference between all females and all males $(P<0.05)$. Italics indicates standard deviations of height $(\mathrm{m})$.

In growth-retarding equivalent.

In median and range. 


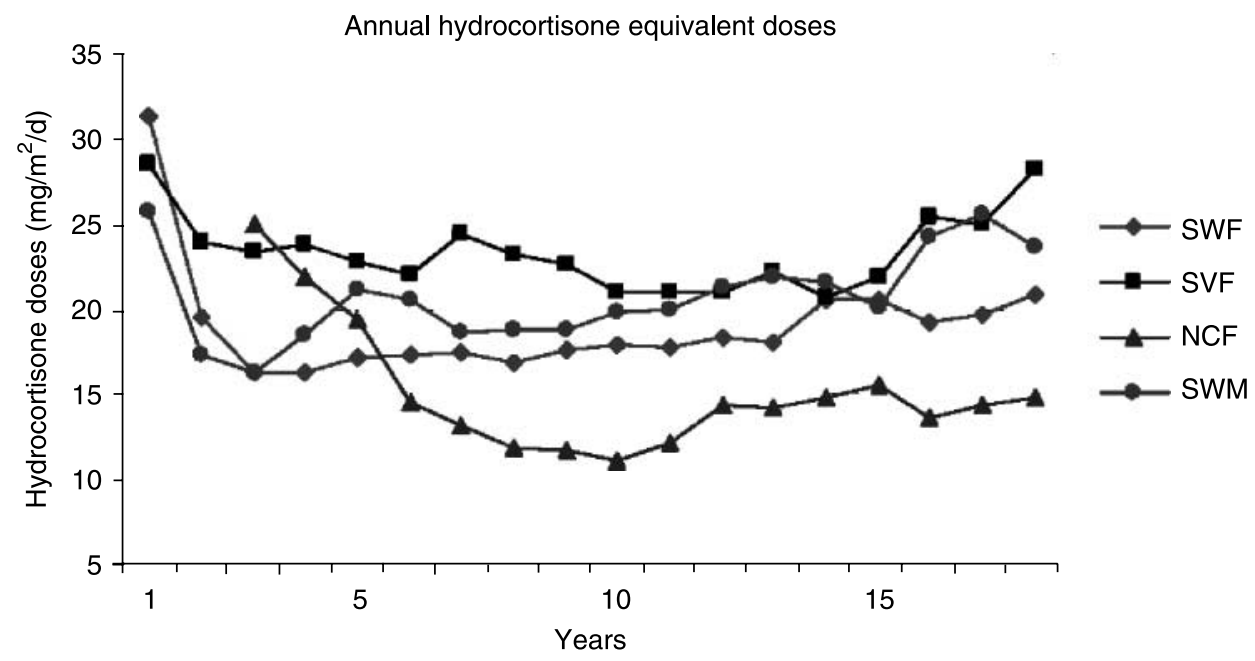

Figure 1 Annual average hydrocortisone growth-retarding equivalent doses from birth to 18 years old. Each year corresponds to a range of 26-38 patients, with NCF beginning the treatment later and some subjects stopping it periodically. SWF, salt-wasting CAH females; SVF, simple virilizing CAH females; NCF, non-classical CAH females; SWM, salt-wasting CAH males.

reached the significance between women and men with the SW form $(P=0.053)$. All women sub-groups (SW, $\mathrm{SV}$, and NC) were comparable for BMD.

Seventeen patients $(44.7 \%)$ had bone demineralization according to WHO criteria, including the ten women (35.7\% of women: 4 SW, 4 SV, and $2 \mathrm{NC}$ ) and seven men (70\% of men: all SW). Among the women, five suffered from lumbar osteopenia alone, two from femoral neck osteopenia alone, and three from both. Five men were affected by lumbar osteopenia and one man by lumbar osteoporosis, and while all of the men had femoral neck osteopenia, only one man had femoral neck osteopenia without lumbar osteopenia (Table 2).

We noted a protective effect of BMI on lumbar $(P=0.006)$ and femoral $(P<0.001)$ BMD for both sexes in the multivariate modeling. There was no change in BMD in women taking exogenous estrogens compared with those who were not.

\section{TCG treatment}

TCG are shown in Table 2. The patients were probably not numerous enough to conclude that there was a difference between those with non-classical and classical forms $(P=0.08)$. Multivariate linear regression demonstrated a negative effect of TCG on lumbar $(P<0.001)$ and femoral T-scores $(P=0.001$; Fig. 2$)$.

\section{TAG dose}

ANOVA showed that TAG differed between groups $(P=0.002$; Table 2$)$ : according to Tukey's comparisons, TAG was lower in patients with non-classical $\mathrm{CAH}$ than with classical CAH $\left(13.2 \pm 4.6\right.$ vs $20.2 \pm 4.9 \mathrm{mg} / \mathrm{m}^{2}$ per $\mathrm{d}$ ); the other groups were comparable. We found a negative effect of TAG on lumbar $(P=0.002)$ and femoral
T-scores ( $P=0.002$; Fig. 3). Multivariate linear regression established that the average glucocorticoid dose during puberty had the most deleterious impact on both lumbar and femoral T-scores $(P=0.02)$. Childhood or adulthood therapy, 0-2 years, seemed less damaging on BMD since they were not emphasized by the multivariate analysis.

\section{Discussion}

In this study, our main objective was to determine whether a bone demineralization in adult patients with 21-hydroxylase deficiency might be related to a high TCG treatment. To do so, we retrospectively calculated the TCG dose of 38 adult subjects with CAH who had achieved their definitive height and undergone DXA.

We found a negative effect of TCG on lumbar and femoral T-scores. Moreover, we demonstrated the same negative effect with TAG, which represented the average daily dose of glucocorticoids that patients received over their entire therapy life period. In fact, $44.7 \%$ of the participants had bone demineralization according to WHO criteria, which is superior to a Gaussian repartition, in which $16 \%$ of the general population is under -1 s.D. These results are reinforced by the fact that patients do not always take their therapy as prescribed notably during childhood and adolescence; in other words, real glucocorticoid intakes may be sometimes lower than those written in files. Our results are reinforced by van Staa's et al. meta-analysis that underlined a strong correlation between cumulative dose and loss of BMD and between mean daily dose and risk of fracture independently of underlying disease requiring corticotherapy, age, and gender (23).

We found fairly normal pubertal development in boys $(11.6 \pm 1.6$ years $)$ and girls $(10.3 \pm 1.8$ years $)$ and a 
Table 2 Results of bone mineral densities, total cumulative glucocorticoid, and total average glucocorticoid treatments.

\begin{tabular}{|c|c|c|c|c|c|c|c|c|}
\hline No. & Form & $\begin{array}{l}\text { T-score } \\
\text { L (DS) }\end{array}$ & $\begin{array}{l}\text { T-score } \\
\text { F (DS) }\end{array}$ & $\begin{array}{l}\text { BMD L } \\
\left(\mathrm{g} / \mathrm{cm}^{2}\right)\end{array}$ & $\begin{array}{l}\text { BMD F } \\
\left(\mathrm{g} / \mathrm{cm}^{2}\right)\end{array}$ & $\begin{array}{l}\text { Years of } \\
\text { treatment }\end{array}$ & $\begin{array}{l}\text { TCG } \\
\left(\mathrm{mg} / \mathrm{m}^{2}\right)\end{array}$ & $\begin{array}{l}\text { TAG } \\
\left(\mathrm{mg} / \mathrm{m}^{2} \text { per } \mathrm{d}\right)\end{array}$ \\
\hline \multicolumn{9}{|c|}{ Females } \\
\hline 1 & SW & 1.35 & 0.57 & 1.175 & 0.881 & 21 & 119574 & 15.6 \\
\hline 2 & SW & 0.56 & 3.09 & 1.092 & 1.151 & 18 & 116289 & 17.7 \\
\hline 3 & SW & 0.28 & 0.62 & 1.062 & 0.886 & 20 & 131400 & 18.0 \\
\hline 4 & SW & 0.24 & 0.05 & 1.058 & 0.825 & 19 & 136510 & 18.7 \\
\hline 5 & SW & 0.01 & 1.06 & 1.034 & 0.933 & 18 & 113661 & 17.3 \\
\hline 6 & SW & 0.00 & 1.13 & 1.033 & 0.941 & 26 & 147095 & 15.5 \\
\hline 7 & SW & -0.10 & -0.16 & 1.023 & 0.803 & 29 & 237104 & 22.4 \\
\hline 8 & sW & -0.38 & -0.50 & 0.993 & 0.767 & 20 & 195640 & 26.8 \\
\hline 9 & SW & -0.57 & -0.02 & 0.973 & 0.818 & 31 & 268166 & 23.7 \\
\hline 10 & SW & -0.77 & -0.79 & 0.952 & 0.735 & 26 & 152789 & 16.1 \\
\hline 11 & SW & -0.90 & -1.02 & 0.939 & 0.711 & 35 & 286160 & 22.4 \\
\hline 12 & SW & -1.12 & 1.21 & 0.915 & 0.949 & 20 & 118990 & 16.3 \\
\hline 13 & SW & -1.75 & -1.64 & 0.849 & 0.644 & 27 & 203013 & 20.6 \\
\hline \multirow[t]{2}{*}{14} & SW & -1.81 & -0.78 & 0.843 & 0.737 & 19 & 91542 & 13.2 \\
\hline & Mean & $-0.35 \pm 0.88$ & $0.20 \pm 1.20$ & $0.996 \pm 0.092$ & $0.842 \pm 0.129$ & $23.5 \pm 5.5$ & $165567 \pm 61953$ & $18.9 \pm 3.8$ \\
\hline 15 & SV & 1.26 & 2.20 & 1.165 & 1.055 & 22 & 118041 & 14.7 \\
\hline 16 & SV & -1.11 & -0.88 & 0.916 & 0.726 & 24 & 177828 & 20.3 \\
\hline 17 & SV & -1.53 & -1.54 & 0.872 & 0.655 & 9 & 82454 & 25.1 \\
\hline 18 & SV & -1.85 & -1.55 & 0.839 & 0.654 & 26 & 239148 & 25.2 \\
\hline \multirow[t]{2}{*}{19} & SV & -2.03 & -0.67 & 0.820 & 0.748 & 36 & 391572 & 29.8 \\
\hline & Mean & $-1.05 \pm 1.34$ & $-0.49 \pm 1.55$ & $0.922 \pm 0.140$ & $0.768 \pm 0.166$ & $23.4 \pm 9.7$ & $201809 \pm 121699$ & $23.0 \pm 5.7$ \\
\hline 20 & NC & 3.54 & 2.87 & 1.405 & 1.127 & 33 & 161403 & 13.4 \\
\hline 21 & NC & 0.69 & 0.84 & 1.105 & 0.910 & 26 & 187902 & 19.8 \\
\hline 22 & $\mathrm{NC}$ & 0.63 & 1.49 & 1.099 & 0.979 & 14 & 77161 & 15.1 \\
\hline 23 & NC & 0.18 & 1.51 & 1.052 & 0.982 & 12 & 27156 & 6.2 \\
\hline 24 & NC & 0.10 & 0.70 & 1.043 & 0.895 & 14 & 43435 & 8.5 \\
\hline 25 & $\mathrm{NC}$ & 0.01 & 0.22 & 1.034 & 0.844 & 9 & 32850 & 10.0 \\
\hline 26 & NC & -0.17 & -0.15 & 1.015 & 0.804 & 18 & 78840 & 12.0 \\
\hline 27 & NC & -0.33 & -1.58 & 0.998 & 0.651 & 34 & 239513 & 19.3 \\
\hline \multirow[t]{2}{*}{28} & NC & -1.65 & -0.37 & 0.860 & 0.780 & 14 & 73584 & 14.4 \\
\hline & Mean & $0.33 \pm 1.38$ & $0.61 \pm 1.30$ & $1.068 \pm 0.145$ & $0.886 \pm 0.138$ & $19.3 \pm 9.3$ & $102427 \pm 75490$ & $13.2 \pm 4.6$ \\
\hline \multicolumn{9}{|c|}{ 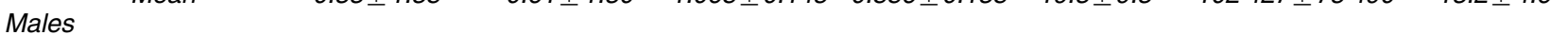 } \\
\hline 29 & SW & 1.60 & 1.20 & 1.239 & 1.044 & 16 & 94024 & 16.1 \\
\hline 30 & SW & -0.01 & 0.07 & 1.090 & 1.080 & 29 & 209510 & 20.5 \\
\hline 31 & SW & -0.40 & -1.80 & 0.987 & 0.718 & 26 & 131911 & 13.9 \\
\hline 32 & SW & -0.90 & -0.10 & 0.928 & 0.871 & 26 & 133809 & 14.1 \\
\hline 33 & sW & -1.56 & -1.31 & 0.920 & 0.835 & 25 & 192538 & 21.1 \\
\hline 34 & SW & -1.96 & -1.84 & 0.875 & 0.777 & 18 & 111690 & 17.0 \\
\hline 35 & sw & -1.99 & -1.89 & 0.872 & 0.772 & 25 & 278313 & 30.5 \\
\hline 36 & SW & -2.28 & -1.16 & 0.840 & 0.922 & 23 & 205678 & 24.5 \\
\hline 37 & SW & -2.41 & -2.09 & 0.826 & 0.800 & 23 & 170419 & 20.3 \\
\hline \multirow[t]{2}{*}{38} & sw & -2.57 & -1.83 & 0.808 & 0.834 & 31 & 313426 & 27.7 \\
\hline & Mean & $-1.25 \pm 1.33$ & $-1.08 \pm 1.10$ & $0.939 \pm 0.135$ & $0.865 \pm 0.118$ & $24.2 \pm 4.5$ & $184132 \pm 71165$ & $20.6 \pm 5.6$ \\
\hline
\end{tabular}

TAG, total average glucocorticoid treatment; TCG, total cumulative glucocorticoid treatment; BMD L, lumbar bone mineral density; BMD F, femoral bone mineral density; T-score L, lumbar T-score; T-score F, femoral T-score. Italics indicates mean results.

mean age of menarche around $13.6 \pm 1.6$ years, which had also been reported by Hughes et al. (24) and Bonfig et al. (25). We noted low final height compared with target height, consistent with former publications (25-28), while the onset of pubertal height was normal. Height gain was also reported as poor during pubertal years in studies conducted by Stikkelbroeck et al. (29) and van der Kamp et al. (30). We observed a small and non-statistical difference between chronological and bone ages for both sexes but only half of the latter were available. This result might thus not be relevant; therefore, we could not exclude that potential bone age advancement might possibly be responsible for a reduced final height.
This underlines the impact of glucocorticoid/androgen balance as more important than altered puberty development in this population. Firstly, hyperandrogenism during infancy due to undertreatment leads to growth velocity acceleration and a premature closure of epiphysial plates (31). Conversely, overtreated children suffer from growth retardation $(32,33)$. One could wonder whether peak bone mass acquired during puberty might be affected by this therapy as total pubertal growth diminishes. Indeed, we underlined that BMD was mostly affected by the glucocorticoid therapy during puberty. This corroborates the work of Gussinyé et al. in which BMD values of adolescent and young adult $\mathrm{CAH}$ patients were significantly lower than 

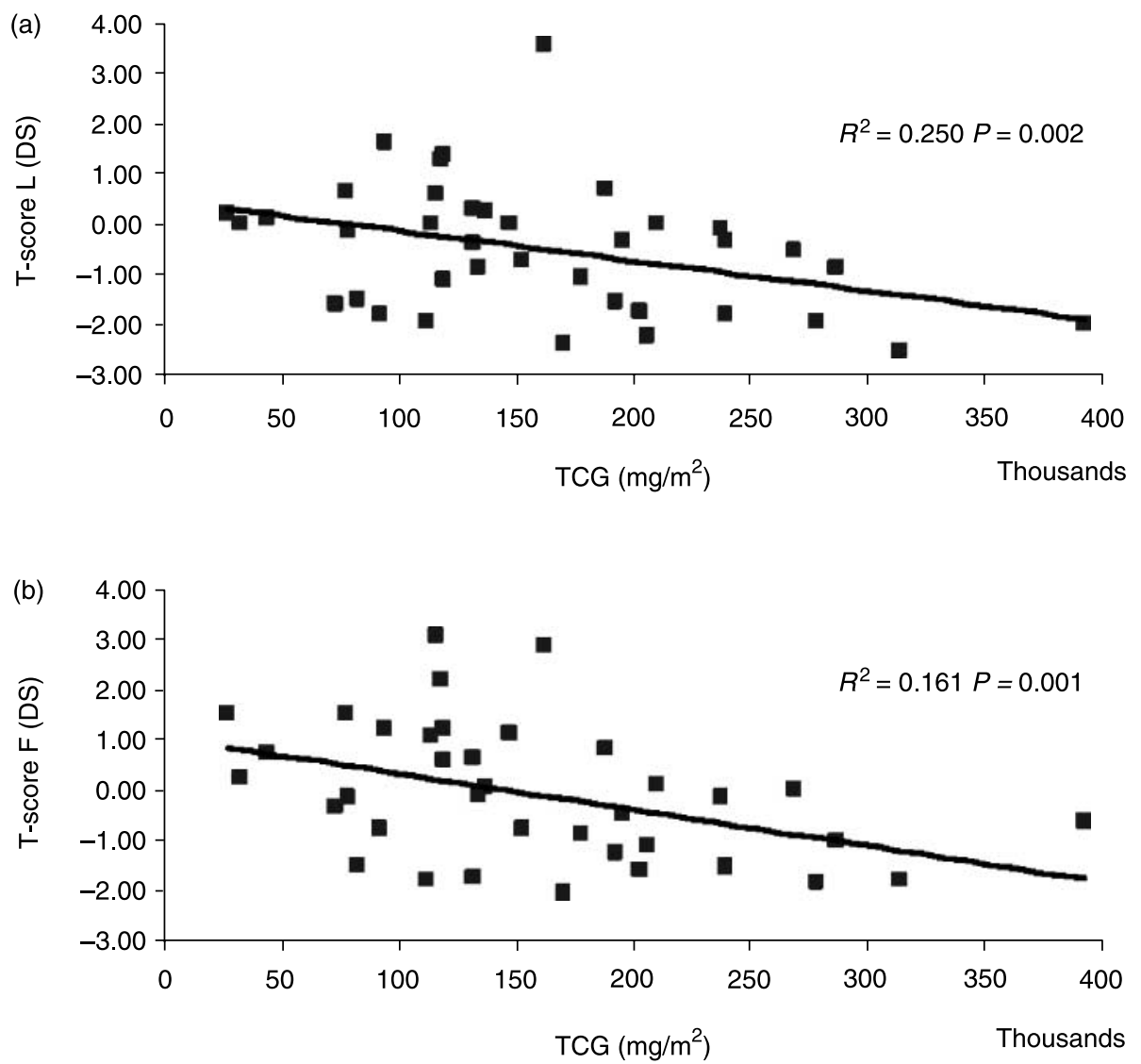

Figure $2 \mathrm{~T}$-score regression lines explained by total cumulative glucocorticoid dose. (a) TCG and lumbar T-score and (b) TCG and female T-score. those of the age- and sex-matched controls, whereas it did not differ between prepubertal patients and controls (34). Multivariate linear regression did not underline another key period, maybe because of the lack of statistical power. Secondly, glucocorticoids may lead to osteoporosis (35), while androgens are known to increase bone formation markers $(36,37)$. Many studies have pointed out that normal endogenous cortisol production is around $7 \mathrm{mg} / \mathrm{m}^{2}$ per $\mathrm{d}$ in healthy people $(38,39)$, whereas clinicians advocate $10-15 \mathrm{mg} / \mathrm{m}^{2}$ per d of exogenous therapy (40), which can bring on corticosteroid side effects in bone and result in subnormal androgen levels. In light of this, non-classical CAH had better BMD than classical CAH groups and their TAG was lower. We were nevertheless unable to determine longitudinal clinical and biological androgenic status, which prevented us from knowing whether low height gain was due to hyperandrogenism or overtreatment and whether or not BMD was influenced by this therapeutic balance.

However, conflicting results were observed in previous studies. This was mainly due to the small number of subjects, their young age, and the heterogeneity of $\mathrm{CAH}$ forms and treatments, and also to the fact that different bone parameters were measured and many factors were used to express glucocorticoid overdose. For example, Jääskeläinen et al. (10) chose a current and mean longterm glucocorticoid dose, (Hagenfeldt et al. (11)), an index of accumulated post-menarchal glucocorticoid medication, (Sciannamblo et al. (13)), the median of the last 7 years of treatment, and a cumulative dose that was calculated exactly over $0.5,2$, and 5 years preceding the investigation (Stikkelbroeck et al. (8)). We opted for the TCG treatment, because it was a long-term parameter that covered medication over an entire lifetime. We lent from work by van Staa et al. on 81 patients in two randomized, double-masked, placebo-controlled trials (23), where they related the TCG to the bone loss.

Furthermore, we observed a large discrepancy between lumbar and femoral T-scores between women and men in this study. Authors of published papers explained that estrogens have more protective action for bone mineralization than androgen $(36,41)$, which could contribute to this result, all the more since the majority of women took exogenous estrogens. In addition, it appears that adult males with $\mathrm{CAH}$ face a dual problem: 1) adrenal steroid overproduction, especially androgen and progesterone that are less protective on BMD than testosterone, might interfere with follicle-stimulating hormone and luteinizing hormone production, resulting in gonadotropin 

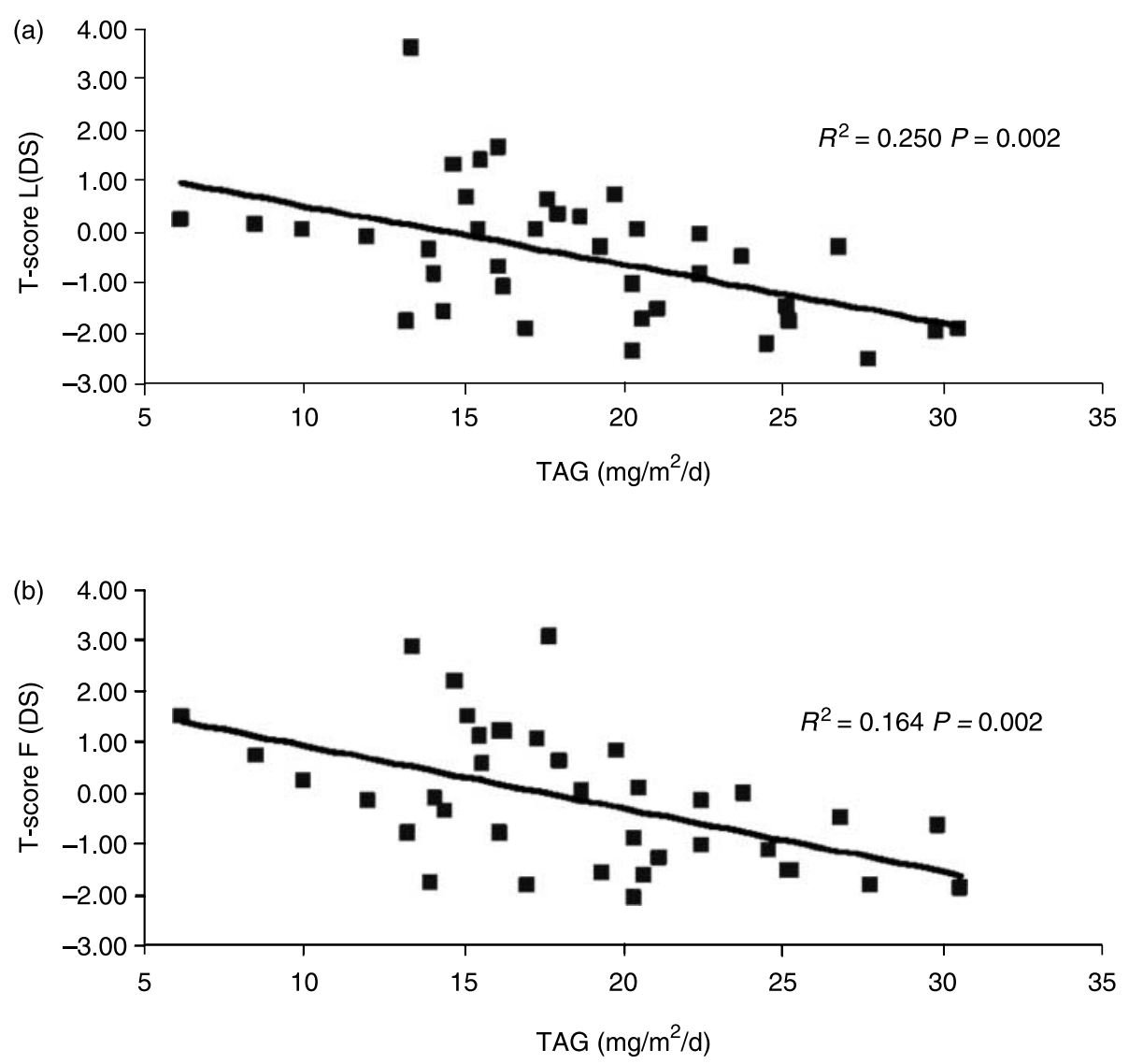

Figure $3 \mathrm{~T}$-score regression lines explained by total average glucocorticoid treatment. (a) TAG and lumbar T-score and (b) TAG and female T-score.

deficiency and consequent small testicular size and lower testosterone levels $(42,43)$, and 2) adrenal rests can interfere directly with the endocrine function of normal testicular tissue in a mechanical way or by local steroid production. Furthermore, supraphysiological doses of glucocorticoids can inhibit gonadotropic axis and also deprive bone of the protector role of testosterone. We showed that BMD in women taking exogenous estrogens compared with those who were not were similar. Nevertheless, we did not distinguish between different hormonal treatments, their duration, or the periods over which they were administered.

BMI was positively correlated with lumbar and femoral bone mineralization in both sexes. This is consistent with the work of Bachelot et al. (14), which suggests that the higher BMI powerfully protects against bone density loss in adult patients with $\mathrm{CAH}$. One could hypothesize two mechanisms: 1) estradiol production by aromatization in fat mass, 2) adipocyte secretion of leptin that regulates bone mass through a hypothalamic relay acting on osteoblasts (44).

Finally, our population was fairly young at $24.6 \pm 5.9$ years, the oldest patient being 39. It is recognized that men and premenopausal women may suffer from glucocorticoid-induced osteoporosis $(45,46)$, and postmenopausal women also have a high risk of fracture during corticosteroid treatment (47). We may suppose that aging patients with $\mathrm{CAH}$ are at a risk of fracture as suggested by Falhammar et al. (15); therefore, preventive methods might be introduced, including physical activity and diet recommendations and vitamin D supplementation if necessary (48). Introducing or increasing $9 \alpha$-fludrocortisone in classical forms could be considered in order to diminish hydrocortisone needs, while some clinicians even tempted it in nonclassical forms. Indeed, it reduces basal ACTH and 17-OHP by inhibiting hypothalamic-adrenal-pituitary axis (49).

We came up against several difficulties when collecting data from pediatric and adult files: sometimes old files were missing and we were not able to fill all the gaps in patients' medical history. This explains the fact that only $62.3 \%$ of our patients were included and that the non-included people were slightly older. Nevertheless, these two groups were comparable for height, BMI, mean current dose of hydrocortisone, and BMD. Moreover, since BMD was shown not to be related to age, the 38 patients included in this research were representative of our population with $\mathrm{CAH}$. We endeavored to constitute a homogeneous group with 
patients who went through the same key period of therapy in infancy and puberty, which is why we took the people with non-classical $\mathrm{CAH}$ with precocious puberty into consideration.

In conclusion, this trial contributes to the determination of bone mineralization in patients with 21-hydroxylase deficiency, based on the TCG dose measurement. We originally established that there was a negative relationship between 1) TCG and TAG and 2) lumbar and femoral BMD. This was effectively illustrated by the non-classical group whose TAG was inferior and bone mineralization was higher. Women might benefit from the preserving effect of estrogens compared with men. BMI also appeared to protect patients from bone loss. In light of this, physicians should bear in mind the potential consequences of glucocorticoids on bone by adjusting the treatment especially during puberty and improving clinical and biological surveillance from infancy. One could suppose that nowadays the youngest patients already benefit from lower doses when comparing with the oldest ones, consequently better results can be expected in the future. Furthermore, preventative measures against corticosteroid-induced osteoporosis should be discussed right from the beginning of glucocorticoid therapy. DXA might be done at least in adult patients on a regular interval. A prospective study taking into account all biases, such as a retrospective look at therapy based on old patient files, and the ensuing irregularities, may confirm our results.

\section{Acknowledgements}

We thank Nicole Delamare for her technical assistance with absorptiometry and Mathieu Coudert for statistical analyses. Zeina Chakhtoura received a fellowship from 'Association surrénales'.

\section{References}

1 White PC \& Speiser PW. Congenital adrenal hyperplasia due to 21-hydroxylase deficiency. Endocrine Reviews 200021 245-291.

2 Raisz LG \& Kream BE. Regulation of bone formation. Part 1. New England Journal of Medicine 1983309 29-35.

3 Hahn TJ, Halstead LR \& Baran DT. Effects of short-term glucocorticoid administration on intestinal calcium absorption and circulating vitamin D metabolite concentration in man. Journal of Clinical Endocrinology and Metabolism 198152 111-115.

4 Hahn TJ. Drug-induced disorders of vitamin D and mineral metabolism. Journal of Clinical Endocrinology and Metabolism 1980 9 107-129.

5 Guo CY, Weetman AP \& Eastell R. Bone turnover and bone mineral density in patients with congenital hyperplasia. Clinical Endocrinology 199645 535-541.

6 Mora S, Saggion F, Russo G, Weber G, Bellini A, Prinster C \& Chiumello G. Bone density in young patients with congenital adrenal hyperplasia. Bone $199618337-341$.
7 Cameron FJ, Kaymakci B, Byrt EA, Ebeling PR, Warne GL \& Wark JD. Bone mineral density and body composition in congenital adrenal hyperplasia. Journal of Clinical Endocrinology and Metabolism $1995 \mathbf{8 0} 2238-2243$.

8 Stikkelbroeck NM, Oyen WJ, van der Wilt GJ, Hermus AR \& Otten BJ. Normal bone mineral density and lean body mass but increased fat mass in young adult patients with congenital adrenal hyperplasia. Journal of Clinical Endocrinology and Metabolism 2003 88 1036-1042.

9 Chritiansen P, Mølgaard C \& Müller J. Normal mineral bone content in young adults with congenital adrenal hyperplasia due to 21-hydroxylase deficiency. Hormone Research 200461 133-136.

10 Jääskeläinen $\mathrm{J} \&$ Voutilainen R. Bone mineral density in relation to glucocorticoid substitution therapy in adult patients with 21-hydroxylase deficiency. Clinical Endocrinology 1996 45 707-713.

11 Hagenfeldt K, Ritzén EM, Ringertz H, Helleday J \& Carlström K. Bone mass and body composition of adult women with congenital virilizing 21-hydroxylase deficiency after glucocorticoid treatment since infancy. European Journal of Endocrinology $2000 \mathbf{1 4 3}$ 667-671.

12 King JA, Wisniewski AB, Bankowski BJ, Carson KA, Zacur HA \& Migeon CJ. Long-term corticosteroid replacement and bone mineral density in adult women with classical congenital adrenal hyperplasia. Journal of Clinical Endocrinology and Metabolism 2006 3 865-869.

13 Sciannamblo M, Russo G, Cuccato D, Chiumello G \& Mora S. Reduced bone mineral density and increased bone metabolism rate in young adult patients with 21-hydroxylase deficiency. Journal of Clinical Endocrinology and Metabolism 200691 4453-4458.

14 Bachelot A, Plu-Bureau G, Thibaud E, Laborde K, Pinto G, Samara D, Nihoul-Fékété C, Kuttenn F, Polak M \& Touraine P. Long-term outcome of patients with congenital adrenal hyperplasia due to 21-hydroxylase deficiency. Hormone Research 200767 268-276.

15 Falhammar H, Filipsson H, Holmdahl G, Janson PO, Nordenskjöld A, Hagenfeldt K \& Thoren M. Fractures and bone mineral density in adult women with 21-hydroxylase deficiency. Journal of Clinical Endocrinology and Metabolism 200792 4643-4649.

16 Marshall WA \& Tanner JM. Variations in the pattern of pubertal changes in girls. Archives of Disease in Childhood $1969 \mathbf{4 4}$ 291-303.

17 Marshall WA \& Tanner JM. Variations in the pattern of pubertal changes in boys. Archives of Disease in Childhood 197045 13-23.

18 Tanner JM, Goldstein H \& Whitehouse RH. Standards for children's height at ages 2-9 years allowing for height of parents. Archives of Disease in Childhood 197045 755-762.

19 Miller WL. The adrenal cortex. In Pediatrics, pp 1584-1613. Eds AM Rudolph \& JIE Hoffman, Norwalk, CT: Appleton \& Lange, 1991.

20 Arlot ME, Sornay-Rendu E, Garnero P, Vey-Marty B \& Delmas PD. Apparent pre- and postmenopausal bone loss evaluated by DXA at different skeletal sites in women: the OFELY cohort. Journal of Bone and Mineral Research 199712 683-690.

21 Cummings SR, Bates D \& Black DM. Clinical use of bone mineral densitometry: clinical applications. Journal of the American Medical Association $2002 \mathbf{2 8 8} 1889-1897$.

22 Prader A, Largo RH, Molinari L \& Issler C. Physical growth of Swiss children from birth to 20 years of age. First Zurich longitudinal study of growth and development. Helvetica Paediatrica Acta 1989 $521-125$.

23 Van Staa TP, Leufkens HG \& Cooper C. The epidemiology of corticosteroid-induced osteoporosis: a meta-analysis. Osteoporosis International 200213 777-787.

24 Hughes IA \& Read GF. Menarche and subsequent ovarian function in girls with congenital adrenal hyperplasia. Hormone Research 198216 100-106.

25 Bonfig W, Bechtold S, Schmidt H, Knorr D \& Schwarz HP. Reduced final height outcome in congenital adrenal hyperplasia under 
prednisone treatment: deceleration of growth velocity during puberty. Journal of Clinical Endocrinology and Metabolism 200792 1635-1639.

26 Pinto G, Tardy V, Trivin C, Thalassinos C, Lortat-Jacob S, NihoulFékété C, Morel Y \& Brauner R. Follow-up of 68 children with congenital adrenal hyperplasia due to 21-hydroxylase deficiency: relevance of genotype for management. Journal of Clinical Endocrinology and Metabolism 200388 2624-2633.

27 Eugster EA, Dimeglio LA, Wright JC, Freidenberg GR, Seshadri R \& Pescovitz $\mathrm{OH}$. Height outcome in congenital adrenal hyperplasia caused by 21-hydroxylase deficiency: a meta-analysis. Journal of Pediatrics 2001138 26-32.

28 Balsamo A, Cicognani A, Baldazzi L, Barbaro M, Baronio F Gennari M, Bal M, Cassio A, Kontaxaki K \& Cacciari E. CYP21 genotype, adult height, and pubertal development in 55 patients treated for 21-hydroxylase deficiency. Journal of Clinical Endocrinology and Metabolism $2003 \mathbf{8 8} 5680-5688$.

29 Stikkelbroeck NM, Van't Hof-Grootenboer BA, Hermus AR Otten BJ \& Van't Hof MA. Growth inhibition by glucocorticoid treatment in salt wasting 21-hydroxylase deficiency: in early infancy and (pre)puberty. Journal of Clinical Endocrinology and Metabolism $2003 \mathbf{8 8} 3525-3530$.

30 Van der Kamp HJ, Otten BJ, Buitenweg N, De Muinck KeizerSchrama SM, Oostdijk W, Jansen M, Delemarre-de Waal HA, Vulsma T \& Wit JM. Longitudinal analysis of growth and puberty in 21-hydroxylase deficiency patients. Archives of Disease in Childhood 200287 139-144.

31 Cameron FJ, Kaymakci B, Byrt EA, Ebeling PR, Warne GL \& Wark JD. Bone mineral density and body composition in congenital adrenal hyperplasia. Journal of Clinical Endocrinology and Metabolism $1995 \mathbf{8 0} 2238-2243$.

32 Silva IN, Kater CE, Cunha CF \& Viana MB. Randomised controlled trial of growth effect of hydrocortisone in congenital adrenal hyperplasia. Archives of Disease in Childhood 199777 214-218.

33 Girgis R \& Winter JS. The effects of glucocorticoid replacement therapy on growth, bone mineral density, and bone turnover markers in children with congenital adrenal hyperplasia. Journal of Clinical Endocrinology and Metabolism 199782 3926-3929.

34 Gussinyé M, Carrascosa A, Potau N, Enrubia M, Vicens-Calvet E, Ibáñez L \& Yeste D. Bone mineral density in prepubertal and in adolescent and young adult patients with the salt-wasting form of congenital adrenal hyperplasia. Pediatrics $1997100671-674$.

35 Saag KG. Glucocorticoid-induced osteoporosis. Endocrinology and Metabolism Clinics of North America 200332 135-157.

36 Arisaka O, Hoshi M, Kanazawa S, Numata M, Nakajima D, Kanno S, Negishi M, Nishikura K, Nitta A, Imataka M, Kuribayashi T \& Kano K. Preliminary report: effect of adrenal androgen and estrogen on bone maturation and bone mineral density. Metabolism 200150 377-379.

37 Finkelstein JS, Klibanski A, Neer RM, Doppelt SH, Rosenthal DI, Segre GV \& Crowley WF Jr. Increases in bone density during treatment of men with idiopathic hypogonadotropic hypogonadism. Journal of Clinical Endocrinology and Metabolism 198969 776-783.

38 Kerrigan JR, Veldhuis JD, Leyo SA, Iranmanesh A \& Rogol AD. Estimation of daily cortisol production and clearance rates in normal pubertal males by deconvolution analysis. Journal of Clinical Endocrinology and Metabolism 199376 1505-1510.

39 Linder BL, Esteban NV, Yergey AL, Winterer JC, Loriaux DL \& Cassorla F. Cortisol production rate in childhood and adolescence. Journal of Pediatrics $1990117892-896$.

40 Consensus statement on 21-hydroxylase deficiency from the Lawson Wilkins Pediatric Endocrine Society and the European Society of Paediatric Endocrinology. Journal of Clinical Endocrinology and Metabolism 200287 4048-4053.

41 Morishima A, Grumbach MM, Simpson ER, Fisher C \& Qin K. Aromatase deficiency in male and female siblings caused by a novel mutation and the physiological role of estrogens. Journal of Clinical Endocrinology and Metabolism 199580 3689-3698.

42 Cabrera MS, Vogiatzi MG \& New MI. Long-term outcome in adult males with classic congenital adrenal hyperplasia. Journal of Clinical Endocrinology and Metabolism 200186 3070-3078.

43 Stikkelbroeck N, Otten BJ, Pasic A, Jager GJ, Sweep C, Noordam K \& Hermus AR. High prevalence of testicular adrenal rest tumours, impaired spermatogenesis, and Leydig cell failure in adolescent and adult males with congenital adrenal hyperplasia. Journal of Clinical Endocrinology and Metabolism 200186 5721-5728.

44 Karsenty G. Convergence between bone and energy homeostases: Leptin regulation of bone mass. Cell Metabolism 20064 341-348.

45 Adinoff AD \& Hollister JR. Steroid-induced fractures and bone loss in patients with asthma. New England Journal of Medicine 1983 309 265-268.

46 Michel BA, Bloch DA, Wolfe F \& Fries JF. Fractures in rheumatoid arthritis: an evaluation of associated risk factors. Journal of Rheumatology 199320 1666-1669.

47 Van Staa TP, Laan RF, Barton IP, Cohen S, Reid DM \& Cooper C. Bone density threshold and other predictors of vertebral fracture in patients receiving oral glucocorticoid therapy. Arthritis and Rheumatism $2003 \mathbf{4 8} 3224-3229$.

48 American College of Rheumatology Ad Hoc Committee on Glucocorticoid-Induced Osteoporosis. Recommendations for the prevention and treatment of glucocorticoid-induced osteoporosis. Arthritis and Rheumatism 200144 1496-1503.

49 Buckley TM \& Schatzberg AF. On the interactions of the hypothalamic-pituitary-adrenal (HPA) axis and sleep: normal HPA axis activity and circadian rhythm, exemplary sleep disorders. Journal of Clinical Endocrinology and Metabolism 2005 90 3106-3114.

Received 15 March 2008

Accepted 20 March 2008 